\title{
Fetal Examination
}

National Cancer Institute

\section{Source}

National Cancer Institute. Fetal Examination. NCI Thesaurus. Code C92714.

A test or diagnostic examination to assess the health status and well being of the fetus. 